\title{
O APRENDIZADO CIENTÍFICO NO COTIDIANO
}

\section{Science learning in everyday life}

\author{
Sergio de Mello Arruda ${ }^{1}$. Marinez Meneghello Passos ${ }^{2}$. Cristina \\ Aparecida de Melo Piza ${ }^{3}$. Rosélis Aparecida Bahls Felix ${ }^{4}$
}

Resumo: O presente artigo tem como objetivo analisar o aprendizado da ciência no cotidiano por meio da utilização do referencial ecológico para o aprendizado em locais e ocupações, conforme apresentado em um relatório recente sobre o aprendizado científico informal. O referencial fornece um conjunto de categorias a priori que permitiram analisar dados obtidos de diálogos entre uma mãe e suas filhas, ocorridos espontaneamente no dia a dia, e de entrevistas realizadas com pessoas que se encontravam em locais públicos, escolhidas ao acaso. Foi possível perceber que, de fato, o aprendizado da ciência permeia as atividades do dia a dia, ocorrendo das mais variadas formas e por meio de diferentes pessoas e atividades.

Palavras-chave: Aprendizagem informal. Aprendizagem científica. Ensino de ciências.

\begin{abstract}
This article aims to analyze the scientific learning in everyday life through the use of an ecological framework for learning in places and pursuits, as shown by a recent report on the informal science learning. The framework provides a set of a priori categories that helped analyze data from dialogues between a mother and her daughters, occurring spontaneously in everyday life and interviews with people in public places, chosen at random. It was possible to see that, indeed, the learning of science permeates the activities of daily life, occurring in many different forms and through different people and activities.
\end{abstract}

Keywords: Informal learning. Scientific learning in daily life. Science teaching.

\footnotetext{
${ }^{1}$ Centro de Ciências Exatas, Departamento de Física, Universidade Estadual de Londrina. Campus universitário, Caixa postal 6001, Londrina, PR, CEP 86051-990, Brasil. <sergioarruda@sercomtel.com.br>. Com apoio do CNPq.

${ }^{2}$ Centro de Ciências Exatas, Departamento de Matemática, Universidade Estadual de Londrina, Londrina, PR, Brasil.

${ }^{3}$ Programa de Pós-Graduação em Ensino de Ciências e Educação Matemática, Universidade Estadual de Londrina, Londrina, PR, Brasil.

${ }^{4}$ Colégio Maxi, Londrina, PR, Brasil.
} 
Arruda, S. M. et al.

\section{Aprendizado por livre escolha, educação formal, informal e não formal}

Há tempos entendemos que o aprendizado de um saber só pode ocorrer por meio do esforço pessoal. Se, como diz Bernard Charlot (2005, p. 96), a "verdade do construtivismo" é que, para construir um saber, é preciso que o sujeito se envolva em uma atividade intelectual, por outro lado, para que isso ocorra, é preciso ter disposição para aprender: é a intenção do sujeito que define se seu aprendizado será significativo ou uma simples memorização (AUSUBEL; NOVAK; HANESIAN, 1978, p. 41). Ou seja: ninguém pode aprender por nós e nós não podemos aprender pelos outros.

Se a aprendizagem significativa é, necessariamente, intencional, ou seja, envolve uma escolha, como fazer com que o aluno escolha aprender? Há anos este tem sido um dos principais dilemas da educação formal. Em um estudo realizado entre 1997 e 2001, por exemplo, foi observado que os professores de Física do Ensino Médio apresentavam duas queixas principais a respeito dos alunos: a falta de interesse e os problemas de compreensão da matemática básica (ARRUDA, 2001, p. 55). Um desses professores assim se expressou sobre esse fato:

Sabe, eu observo que no período noturno falta completamente prérequisito. O aluno está superfraco. Tem uma turma de terceiro ano que, olha... Você pode entrar com a maior motivação, que você sai desanimado. [...] Eles não têm conhecimento de nada. Eles não têm interesse nem vontade. (ARRUDA, 2001, p. 56)

Temos observado que problemas como esses vêm se repetindo desde então, e surgem nas falas não só de professores em serviço, mas de estagiários de diversas licenciaturas que temos acompanhado nos últimos anos (ANTUNES, 2007; BACCON, 2005).

Não queremos aqui explorar profundamente as razões do desinteresse de muitos estudantes em relação aos saberes escolares. Mas é evidente que o problema extrapola os muros da escola e toca em questões culturais. Uma pesquisa realizada nos Estados Unidos da América (EUA) há cerca de dez anos revelou o seguinte perfil para a população americana, no que diz respeito a conteúdos científicos: $50 \%$ das pessoas leem jornais diariamente, incluindo matérias sobre Ciência e Tecnologia (C\&T); 15\% leem, mensalmente, revistas de C\&T; a maioria assiste um ou mais filmes científicos a cada mês; $2 / 3$ dos adultos foram a um museu no último ano; 1/3 comprou um ou mais livros de C\&T no último ano (DIERKING, 2005, p. 151). E como é a situação no Brasil?

Um levantamento recente, realizado por J. Leiva Cultura e Esporte, Datafolha e Fundação Getúlio Vargas (FGV), divulgada no jornal Folha de São Paulo (SOUSA, 2010a, 2010b), revelou que: $40 \%$ dos paulistas não costumam ir ao cinema, $60 \%$ não costumam ir ao teatro, $61 \%$ não costumam ir a museus. Segundo o levantamento, as pessoas justificaram esse comportamento com frases do tipo: 'Não me interesso/ não gosto/ não me sinto bem fazendo'. Mediante essas informações, o que podemos inferir? A situação, no país como um todo, não deve diferir muito disso. Será que isso significa que as pessoas, no Brasil, não estão querendo aprender nada sobre Ciência e Tecnologia? Talvez não seja bem assim. 
Tomemos outra pesquisa, também realizada nos EUA: nela foram entrevistadas, por telefone, duas mil pessoas, às quais se perguntou sobre como aprenderam ciência. As respostas foram: $1 / 3$ aprendeu tópicos de ciências na escola; $1 / 4$ aprendeu ciência no trabalho; e 1/ 2 aprendeu ciências em momentos de lazer (DIERKING, 2005, p. 151). Como podemos ver, muitas pessoas estão aprendendo ciência mais fora da escola do que dentro dela. De fato, como diz Dierking (2005, p. 147, tradução e grifo nosso):

No mundo todo, as sociedades estão assistindo a uma explosão virtual de oportunidades para o aprendizado por livre escolha $a^{5}$, um aprendizado que é guiado pelas necessidades e interesses da pessoa e em que as pessoas se envolvem ao longo da vida para encontrar mais sobre aquilo que é útil, atrativo ou de simples interesse para elas.

Perguntamos então: será que temos evidências de que, no Brasil, as pessoas também estão aprendendo ciência por livre escolha, em situações informais, no trabalho, no dia a dia ou na família? Este trabalho dá uma resposta positiva a essa questão, como veremos.

$\mathrm{O}$ aprendizado por livre escolha está no centro das investigações sobre a aprendizagem informal e não formal. Nos últimos anos, tem-se observado, no Brasil, um aumento significativo de pesquisas sobre tais modalidades de educação. Um levantamento recente realizado com a produção bibliográfica das principais revistas do ensino de ciências no Brasil revelou que $95,5 \%$ do total de artigos publicados sobre o tema educação não formal estão concentrados nos últimos 14 anos investigados, ou seja, de 1995 a 2009 (ALVES; PASSOS; ARRUDA, 2010, p. 25).

No exterior, existe uma vasta literatura publicada a respeito. Podemos citar, por exemplo, um relatório de 2002, publicado pela Universidade de Leeds (COLLEY; HODKINSON; MALCOLM, 2002), em que inúmeros trabalhos são citados.

$\mathrm{Na}$ literatura da área, é padrão separar o aprendizado em três categorias: formal, informal e não formal - e podemos encontrá-los, em diversos trabalhos, apresentados desta forma. Uma das definições mais completas pode ser observada em um documento da União Europeia, baseado em pesquisas sobre o aprendizado ao longo da vida ou, em inglês, lifelong learning:

Aprendizado formal: aprendizado fornecido tipicamente por uma instituição de educação ou treinamento, estruturado (em termos de objetivos de aprendizagem, tempo de aprendizado ou sustentação) e que leva a uma certificação. É intencional, do ponto de vista do aprendiz. Aprendizado não formal: não é fornecido por uma instituição educacional ou de treinamento e não leva à certificação. Entretanto, é estruturada (em termos de objetivos, tempo e suporte à aprendizagem). É intencional, do ponto de vista do aprendiz.

${ }^{5}$ Em inglês: free choice learning. 
Arruda, S. M. et al.

Aprendizado informal: resulta das atividades do dia a dia, relacionadas ao trabalho, família ou lazer. Não é estruturada (em termos de objetivos, tempo e suporte à aprendizagem) e normalmente não leva a uma certificação. O aprendizado informal pode ser intencional, mas na maioria das vezes é não intencional ou incidental. (EUROPEAN COMMISSION, 2001, p. 32-33, tradução nossa)

Há, ainda, uma tendência de identificar a educação não formal com a que ocorre em centros e museus de ciência:

[...] a educação não formal pode ser definida como a que proporciona a aprendizagem de conteúdos da escolarização formal em espaços como museus, centros de ciências, ou qualquer outro em que as atividades sejam desenvolvidas de forma bem direcionada, com um objetivo definido. (VIEIRA; BIANCONI; DIAS, 2005, p. 21)

De um modo mais geral, o que distingue a educação formal da informal é que a primeira "está presente no ensino escolar institucionalizado" (BIANCONI; CARUSO, 2005, p. 20), enquanto a informal é aquela em que "qualquer pessoa adquire e acumula conhecimentos, através de experiência diária em casa, no trabalho e no lazer" (BIANCONI; CARUSO, 2005, p. 20).

Na década de 1970, o aprendizado formal foi visto como superior ao informal, por ser proposicional, científico e generalizável; posteriormente, argumentou-se em sentido contrário, ou seja, que o aprendizado informal é que seria superior, sendo o aprendizado de uma linguagem o principal exemplo (COLLEY; HODKINSON; MALCOLM, 2002). Entretanto, a principal conclusão que consta do relatório de Leeds é que "é difícil fazer uma distinção clara entre o aprendizado formal e o informal, pois, frequentemente há uma superposição entre os dois" (MCGIVNEY, 1999 apud COLLEY; HODKINSON; MALCOLM, 2002, tradução nossa).

Os estudos apontam que, praticamente, não existem situações de aprendizagem onde elementos formais ou informais estão completamente ausentes.

Uma posição que nos pareceu mais adequada a respeito das diferenças e semelhanças entre os três tipos de aprendizagem é a que coloca a educação formal e a informal em um contínuo: de um lado, "as experiências e encontros não antecipados que resultam em um aprendizado incidental" (STERN; SOMMERLAD, 1999 apud COLLEY; HODKINSON; MALCOLM, 2002, tradução nossa) e, de outro, "os programas formais que levam à qualificação” (STERN; SOMMERLAD, 1999 apud COLLEY; HODKINSON; MALCOLM, 2002, tradução nossa); a aprendizagem não formal, identificada usualmente como a aprendizagem em museus, centros de ciência, zoológicos etc., se situaria em algum ponto entre uma extremidade e a outra. 


\section{A aprendizagem científica informal: focos e configurações}

Em 2009, sob a coordenação do National Research Council (Conselho Nacional de Pesquisa) dos EUA, foi publicado um relatório bastante amplo sobre a aprendizagem informal, com o título 'Learning science in informal environments: people, places e pursuits'.

Neste relatório, o objetivo maior é examinar as possibilidades para o aprendizado de ciências em situações de informalidade:

Ambientes informais incluem uma ampla gama de configurações, como conversas familiares em casa, visitas a museus, centros de ciência, ou outros ambientes planejados, além de atividades diárias como jardinagem, atividades recreativas como caminhadas e pesca e participação em clubes. Praticamente todas as pessoas de todas as idades e formações se envolvem em atividades que podem apoiar a aprendizagem das ciências no decurso da vida diária. (NATIONAL RESEARCH COUNCIL, 2009, p. 1, tradução nossa)

Não aparece explicitamente a expressão "educação não formal"; entendemos, então, que essa modalidade de aprendizado pode ser incluída entre as possibilidades do aprendizado informal. Segundo o relatório, as experiências de aprendizagem de ciência em ambientes informais podem ser caracterizadas como "motivadoras, guiadas pelos interesses do aluno, voluntárias, pessoais, continuadas, contextualmente relevantes, colaborativas, não lineares" (NATIONAL RESEARCH COUNCIL, 2009, p. 11, tradução nossa), e que levam à percepção de que "aprender a ciência pode ser prazeroso, relevante e gratificante" (NATIONAL RESEARCH COUNCIL, 2009, p. 11, tradução nossa).

\section{Um "referencial ecológico" para a aprendizagem informal}

Os pesquisadores em educação científica informal distinguem três concepções amplas de aprendizado: lifelong learning, que se refere à aquisição de conhecimentos e competências científicas fundamentais ao longo da vida, geralmente associados a algumas necessidades e interesses que podem variar com o tempo; life-wide learning, que se refere ao fato de que o aprendizado informal ocorre à medida que as pessoas circulam nas mais variadas situações e ambientes que encontram em sua vida; life-deep learning, está associada ao aprendizado de aspectos culturais, a valores morais, éticos, religiosos e sociais que eventualmente guiam a ação e o juízo que as pessoas fazem sobre si mesmas e sobre os outros (NATIONAL RESEARCH COUNCIL, 2009, p. 28).

\footnotetext{
${ }^{6}$ Aprendendo ciência em ambientes informais: pessoas, lugares e ocupações (tradução nossa).
} 
Arruda, S. M. et al.

Nos Estados Unidos, a educação informal é muito valorizada. É considerada um dos três pilares do sistema educacional americano, os outros sendo a escola básica e a Educação Superior. Para o Departamento de Educação daquele país, a aprendizagem informal seria necessária para assegurar a competitividade econômica dos EUA, em particular, a capacidade das instituições educacionais de produzirem cidadãos cientificamente alfabetizados e futuros cientistas, engenheiros, matemáticos etc. (NATIONAL RESEARCH COUNCIL, 2009, p. 13).

O já citado relatório define um 'referencial ecológico para a compreensão do aprendizado em lugares e ocupações" ${ }^{7}$. Trata-se de uma teoria ampla, que procura integrar diversas perspectivas relacionadas ao aprendizado informal da ciência. Esse referencial incorpora princípios discutidos em dois outros relatórios que tratam do aprendizado científico: "Taking science to school: learning and teaching science in grades K-8' (NATIONAL RESEARCH COUNCIL, 2007) e 'How people learn: brain, mind, experience and school' (NATIONAL RESEARCH COUNCIL, 1999).

O "referencial ecológico" utiliza três "olhares" para examinar os ambientes de aprendizagem: um olhar centrado na pessoa, que foca em fenômenos intrapsicológicos, tais como o desenvolvimento do interesse, as respostas afetivas, a identidade, os conhecimentos prévios, as diferenças entre peritos e novatos e a metacognição; um olhar centrado no lugar, que leva em consideração os lugares onde se dá o aprendizado e as atividades típicas a eles associadas; e um olhar centrado na cultura, que assume, baseado em Vygotsky, que todo aprendizado é um processo cultural (NATIONAL RESEARCH COUNCIL, 2009, p. 34-41).

\section{Focos (strands) do aprendizado científico informal}

O aprendizado científico em ambientes informais é concebido, no relatório do National Research Council (2009, p. 42, tradução nossa), como fios de uma corda - strands of a rope - "tecidos para produzir experiências, ambientes e interações sociais", atraindo "pessoas de todas as idades e experiências na direção de uma maior compreensão, fluência e perícia científicas". Preferimos, neste trabalho, denominar tais 'strands' de focos do aprendizado científico informal. O relatório considera seis focos de aprendizagem, conforme descritos no Quadro 1.

Um aspecto importante desses focos é que eles estão interligados, de tal forma que o progresso em um deles contribui para o desenvolvimento dos outros (FENICHEL; SCHWEINGRUBER, 2010, p. 2-5).

\footnotetext{
${ }^{7}$ No original: ecological framework for understanding learning across places and pursuits. 
Quadro 1. Focos do aprendizado científico informal.

1. Desenvolvimento do interesse pela ciência (foco 1). Refere-se à motivação, ao envolvimento emocional, à
curiosidade, à disposição de perseverar no aprendizado da ciência e dos fenômenos naturais, que podem
afetar a escolha de uma carreira científica, e levar ao aprendizado científico ao longo da vida.

Fonte: National Research Council (2009, p. 41-47, tradução nossa).

\section{Configurações (venues) do aprendizado científico informal}

O relatório do National Research Council (2009) localiza três configurações - venues - para o aprendizado informal da ciência: ambientes informais do cotidiano, ambientes planejados e programas fora da escola e para adultos.

O aprendizado cotidiano permeia a vida diária das pessoas, incluindo experiências e atividades diversas, que podem se estender durante todo o tempo de vida. Exemplos: conversas diárias na família e com colegas, os hobbies pessoais, o envolvimento com a mídia e o uso da tecnologia (NATIONAL RESEARCH COUNCIL, 2009, p. 47).

Os ambientes planejados incluem museus, centros de ciência, jardins botânicos, zoológicos, aquários e livrarias. Embora esses ambientes sejam estruturados como instituições, a experiência a ser realizada nesses espaços usualmente é determinada pelos seus interesses (NATIONAL RESEARCH COUNCIL, 2009, p. 48).

Os programas fora da escola e programas para adultos incluem programas de verão, aprendizado nas férias, programas para a terceira idade etc. Podem ser parcialmente organizados, mas a escolha, usualmente, depende do aprendiz ou do responsável por ele. Usualmente, tratase de experiências guiadas por um monitor ou um profissional treinado (NATIONAL RESEARCH COUNCIL, 2009, p. 48). 
Arruda, S. M. et al.

\section{Os dados apresentados neste trabalho}

Neste trabalho focalizamos situações de aprendizagem que ocorrem no dia a dia. Serão apresentados dois conjuntos de dados, constituídos por fragmentos de diálogos. O primeiro trata de anotações de conversas espontâneas ocorridas entre uma mãe e suas filhas; o segundo foi obtido por meio de entrevistas com pessoas que se encontravam em ambientes públicos da cidade de Londrina, PR, Brasil.

Nos diálogos apresentados, procuramos indicar, entre parênteses, os focos de aprendizagem informal neles identificados. Lembramos que os seis focos da aprendizagem informal, conforme apresentados neste trabalho, são os seguintes:

1. Desenvolvimento do interesse pela ciência (foco 1).

2. Compreensão do conhecimento científico (foco 2).

3. Envolvimento com o raciocínio científico (foco 3).

4. Reflexão sobre a natureza da ciência (foco 4).

5. Envolvimento com a prática científica (foco 5).

6. Identificação com o empreendimento científico (foco 6).

As tomadas de dados fizeram parte de uma das tarefas de uma disciplina do Programa de Pós-graduação em Ensino de Ciências e Educação Matemática da Universidade Estadual de Londrina (UEL).

\section{Exemplo 1: aprendizagem informal no cotidiano familiar}

Os dados apresentados e analisados nesta seção referem-se a trechos de três diálogos ocorridos entre uma mãe e suas filhas, durante o primeiro semestre de 2010. As conversas aconteceram de maneira inesperada e espontânea, em situações e ambientes diversos durante a realização de atividades familiares corriqueiras. A mãe (professora de Matemática do Ensino Básico) estava preparada para memorizar os diálogos e anotá-los posteriormente. As filhas são duas crianças nominadas como Criança 1 (de sete anos) e Criança 2 (de cinco anos).

Podemos ver que, nos diálogos abaixo, a mãe atua como professora e as crianças como aprendizes. Trata-se, portanto, de uma situação de ensino e aprendizagem informal, baseada na comunicação cotidiana e comum entre as pessoas. Cada um desses diálogos pode ser visto como um diálogo de ensino e aprendizagem científica informal, que estaremos designando, simplesmente, como diálogos de aprendizagem informal - DIAI. Estamos convictos de que tais diálogos são mais comuns na vida diária do que poderíamos imaginar. De fato, o aprendizado informal pode ocorrer a qualquer momento, em situações diversas do dia a dia. Os focos da aprendizagem informal, ou strands, estão indicados entre parênteses ao final de cada frase.

Diálogo A (no carro, voltando da escola).

Criança 1: Mãe, vamos à pracinha?

Mãe: Não, porque está muito frio. O dia que tiver (sic) mais quente, nós vamos. O Sol já está indo embora! (foco 3) 
Criança 1: O Sol está indo para o Japão? (foco 1-3)

Mãe: Não! O Sol está no mesmo lugar. A Terra é que está se mexendo. (foco 3)

Criança 1: Como a gente não sente? (foco 1-3)

Mãe: $A$ Terra mexe devagarzinho. A gente fica em cima. (foco 3 )

Criança 1: A gente fica de ponta-cabeça? (foco 1-3)

Mãe: Fica, mas não cai. (foco 3)

Criança 1: Por que não cai? (foco 1-3)

Mãe: Por causa da gravidade. É uma força que puxa a gente pra baixo, pra Terra, igual um imã. (foco 3)

No diálogo A, a conversa principia com uma proposta de atividade lúdica por parte da criança (ir à pracinha), mas que enfrenta a resistência da mãe devido ao tempo frio. O DIAI propriamente dito se inicia com a explicação da mãe (foco 3: geração de explicações) envolvendo conteúdos relacionados com calor e temperatura (frio, quente). A curiosidade da criança é disparada (foco 1) a partir de um comentário complementar da mãe (o sol está indo embora). A pergunta da criança (indo para o Japão?) e o restante do DIAI aparentemente revelam que ela já tem ideia de que a Terra é redonda e que o Japão se situa no lado oposto, embora não entenda ainda o movimento da Terra. A tentativa da mãe de explicar o movimento da Terra enfrenta novas questões da criança, em um processo semelhante a uma investigação científica (foco 3: levantamento de problemas, formulação de hipóteses, geração de explicações, formulação de novo problema etc.). Podemos observar o esforço da mãe para explicar a gravidade, tendo de utilizar uma analogia com o magnetismo, provavelmente mais conhecido pela criança. A mãe também comete algumas imprecisões durante sua fala, como a afirmação de que a Terra mexe devagarzinho, quando sua velocidade de rotação é de, aproximadamente, $1.700 \mathrm{~km} /$ h. Anotamos a presença dos seguintes termos científicos neste DIAI: quente, frio, Sol, Terra, gravidade, força e ímã.

Este diálogo centrou-se apenas nos focos 1-3 nas falas da criança e no foco 3 nas falas da mãe, se alternando sucessivamente, construindo uma sequência do tipo foco 1-3/ foco 3 /foco $1-3$ /foco 3 .

$\mathrm{Na}$ sequência, descrevemos parte de outro diálogo registrado.

Diálogo B (novamente no carro).

Criança 2: Por que as folhas das árvores balançam com vento? (foco 1-3)

Mãe: Elas são leves. A força do vento consegue balançá-las. (foco 3)

Criança 2: Por que o tronco não se mexe também? (foco 1-3)

Mãe: Porque ele está preso no chão pelas raízes e é mais pesado. Para balançá-lo precisaria de um vento mais forte. (foco 3)

Criança 2: Mas como o Pato Donald consegue carregar a árvore? (foco 1-4) Mãe: Ele não conseguiria se fosse de verdade (foco 4). É só um desenho animado. (foco 4)

O diálogo B já é todo um DIAI que se inicia a partir de uma observação direta da criança sobre o movimento das folhas de uma árvore, revelando o interesse e a curiosidade da criança (foco 1) e gerando o início de uma sequência de questões de investigação a partir de 
Arruda, S. M. et al.

um problema gerador ${ }^{8}$ (foco 3 ). Temas relacionados à força peso (leve, pesado) e às partes das plantas (raízes, tronco, folhas) vêm na continuidade, mostrando como a interdisciplinaridade surge naturalmente. Entretanto, ultrapassando o terreno dito científico para cair nos desenhos animados, que, como os fenômenos naturais, também podem ser disparadores de questões de investigação, nesse caso, também foi possível encontrar temas metacientíficos ligados à noção de verdade e realidade (Mas como o Pato Donald consegue carregar a árvore? Ele não conseguiria se fosse de verdade), ou seja, relativos ao foco $4 \mathrm{da}$ aprendizagem informal (temas relativos à natureza da ciência). A mãe, como no diálogo A, assume a função explicativa da professora (foco 3) durante toda a conversa. Os termos científicos presentes são: folhas, tronco, raízes, força, leve, pesado, verdade.

Podemos ver que a estrutura geral desse DIAI no início é a mesma do anterior, ou seja, a sequência foco $1-3 /$ foco $3 /$ foco $1-3$ /foco 3 , mas que, incorpora, repentinamente, o foco 4 .

Diálogo C - Situação: em casa mexendo com plantas.

Criança 1: As flores que murcharam estão mortas? (foco 1-3)

Mãe: Sim, mas a planta está viva. As flores ficam bonitas e depois murcham. (foco 3)

Criança 1: Mas como não as vemos respirando? (foco 1-3)

Mãe: Não dá para ver. Elas respiram, mas não como nós. Elas respiram pelas folhas. Elas respiram gás carbônico e liberam oxigênio, on seja, elas tiram gás carbônico do ar e soltam oxigênio. Quando nós respiramos, liberamos gás carbônico e precisamos do oxigênio. Você percebe que precisamos do oxigênio que as plantas liberam? (a mãe explica de novo, neste momento) (foco 3)

Criança 1: Ahbhb! A gente precisa das plantas para respirar melhor. (foco 2) Mãe: Não somos só nós que liberamos gás carbônico. Os carros também. (foco 3)

Criança 1: Mas por quê? Eles respiram como nós? (foco 1-3)

Mãe: Não. Mas aí eu já não sei te explicar.

Criança 1: Rsrsrs. Só as plantas "fazem" o oxigênio? (foco 1-3)

Mãe 1: Não. Boa parte é produzida pelas algas. São plantinhas que vivem no mar. (foco 3)

Como no diálogo anterior, a situação de aprendizagem é deflagrada pela observação direta da criança, o que a faz produzir uma sequência de investigação a partir de um problema

\footnotetext{
${ }^{8}$ Denominamos problema gerador a um problema que desempenha um papel organizador e direcionador das ações que vão ser realizadas em um processo investigativo (ARRUDA; NARDI, 1992).

${ }^{9}$ Agradecemos ao avaliador deste artigo por nos chamar a atenção para o erro conceitual presente neste diálogo. Segue a reprodução de sua observação: “Trata-se de um erro conceitual comum no senso comum que é a confusão entre respiração e fotossíntese das plantas, como se fossem o mesmo fenômeno fisiológico. $\mathrm{Na}$ respiração das plantas, não há consumo de gás carbônico e liberação do oxigênio, mas o inverso (igual ao processo nos animais)".
} 
gerador (foco 1-3). Sem que saibamos exatamente por que, a criança se inquieta com o tema da respiração das plantas. A partir das informações oferecidas pela mãe (foco 3) ela consegue tirar conclusões por si mesma, evidenciando aprendizagem de conteúdo científico (foco 2: $a$ gente precisa das plantas para respirar melhor). A mãe introduz (inadvertidamente) outro elemento na conversa, o carro, o que gera novo problema para a criança (eles respiram como nós?), deixando a mãe sem explicação. Os termos científicos presentes no diálogo são: flores, plantas, respiração, gás carbônico, oxigênio e algas.

A estrutura geral do DIAI é semelhante ao da encontrada no diálogo A, ou seja, a sequência foco 1-3/foco 3/foco 1-3/foco 3 etc., com o surgimento de evidências de aprendizagem (foco 2).

\section{Comentários}

Poderíamos pensar que os DIAI relatados acima tenham sido induzidos pelo fato de a mãe ser realmente professora. Entretanto, é possível que este não seja sempre o caso, pois assumir a posição daquele que ensina não é privilégio apenas do professor de profissão. Além disso, é possível observar os DIAI entre crianças de mesma idade ou idades diferentes, entre adultos quaisquer etc.

No caso dos DIAI com crianças, apresentados acima, é possível observar que eles foram disparados, sobretudo, a partir da curiosidade despertada por algum fenômeno natural. Entretanto, a própria fala da mãe também pode exercer esse papel. Estão ligados a contextos, momentos e situações específicas, e não são, em geral, programados: uma situação de aprendizagem informal se apresenta inesperadamente e as pessoas nem se dão conta disso. Pais, adultos ou, mesmo, outras crianças podem estar agindo como mediadores no processo de aprendizagem, sem saber dos papéis que estão a desempenhar.

Os conteúdos envolvidos em um DIAI podem ser os mais variados possíveis. Em geral, vão se sucedendo uns aos outros, em um movimento de articulação dos assuntos, conceitos e áreas de conhecimento de forma interdisciplinar. Obviamente, não há uma sequência de conteúdos predefinida, já que se trata de um aprendizado movido pela livre escolha.

Usualmente, um diálogo envolve mais de um foco de aprendizagem (strands). Vimos que, nos casos analisados, os mais comuns foram os focos 1 e 3 . Ou seja, os DIAI encontrados estão mais ligados ao conteúdo científico. Mas a presença do foco 4 não foi surpresa, já que o ser humano, usualmente, procura testar a validade do seu conhecimento, como também ficará evidente no próximo exemplo. Falas que revelam um aprendizado (foco 2) também não foram muito comuns nas situações analisadas neste trabalho. No entanto, certamente, o aprendizado do conteúdo está ocorrendo; apenas não aparece explicitamente nas falas.

\section{Exemplo 2: aprendizagem informal sobre fenômenos naturais}

No caso do exemplo 2, a metodologia de tomada de dados foi planejada previamente. Foram utilizadas entrevistas semiestruturadas, com duração de dez a 15 minutos. Os participantes foram escolhidos ao acaso, entre as pessoas que circulavam em ambientes públicos da cidade de Londrina, PR, Brasil. Foram escolhidos locais de fácil acesso e com um bom número de pessoas. As entrevistas principiavam com uma questão geral relacionada a fenômenos e catástrofes naturais ocorridas em 2010 (sobretudo as fortes chuvas e enchentes), solicitando, 
Arruda, S. M. et al.

ao entrevistado, que apresentasse sua compreensão a respeito, as fontes onde buscava informações etc.

Com relação aos dados, serão apresentados trechos de duas entrevistas. A pesquisadora está sendo designada pela letra P e os entrevistados pela letra E (como são dois entrevistados, adotaram-se os códigos E1 e E2). As entrevistas foram transcritas literalmente, sofrendo alguma edição para dar mais consistência ao texto, sem prejuízo do sentido da fala do entrevistado.

Entrevista 1 (E1, 36 anos, empregada doméstica. Escolaridade: $4^{\circ}$ ano primário, hoje Ensino Fundamental I. Entrevistada na Feira da Lua, da Avenida Inglaterra, zona sul de Londrina, PR).

P: Você soube de algum problema causado pelo excesso ou falta de chuvas ocorridas no Brasil este ano?

E1: Sube sim... no Rio de Janero... lá caíram um monte de barraco e matou um montão de gente.

P: Em sua opinião, qual é a causa dessas ocorrências?

E1: Eu acho que isso tudo tem a vê com a sujera que a gente mesmo faiz: (foco 3). [...] Veja bem! Tem o lixo que a gente joga em lugar errado..., tem a sujera de gordura que jogamo na pia que vai pros encanamento e intopi tudo. Essa gordura também acaba poluino as água do rio e acaba faltano água nas nossas casa. (foco 3).

P: E as chuvas? Por que chove tanto em certas regiões, como aconteceu no Rio de Janeiro?

E1: As chuva tem a vê com a fumaça dos carro..., com as queimada das mata e essas coisa que dexa o ar cheio de fumaça (foco 3). Essa fumaça toda vai subino, subino e para lá no alto "onde acaba" o céu. [...] Quis dizế, o final onde fica o ar em volta da Terra. (foco 3)

P: A atmosfera?

E1: Essa mesmo. Quando a fumaça fica lá no alto da atmosfera ela não dexa o calor do sol sair pru infinitu e fica muito quente aqui pra nóis na Terra. Acontece o tal do efeito... insufa (foco 3) que o povo fala.

P: Quem é o povo que fala sobre o efeito estufa?

E1: Os locutor dos rádio, os reporte da televisão e umas pessoa que conversa no ônibus que eu pego pra vim pro trabalho. (foco 5)

P: E então, o que acontece depois que a temperatura aumenta por causa do efeito estufa?

E1: Bem, depois que fair. muito calor, por causa do efeito instufa...(foco 2) os rio, os lago e até o mar, evapora mais rápido e o vapor da água vai subindo, subindo e forma as nuvi. Quando as nuvi tão cheia de água elas cai... chove (foco 3). Bão, num sei se é assim mesmo, foi minha filha que aprendeu na iscola outro dia e veio falano isso em casa. (foco 3-5)

P: Você gosta dessa parte da ciência que fala das mudanças de temperatura? 
E1: A gente precisa gostá... Mas, não é só por isso. Eu sempre gosto de olha pro céu pra vê se a chuva vem vindo (foco 1). No sitio, quando eu era pequena, meu avô costumava dizế:

- Fia, quando você olha pro céu e percebe um círculo em roda da Lua você procura vê se o círculo tá perto ou longe dela. Quando o círculo tá perto da Lua, qué dirêe que a chuva tá longe da terra e, quando o círculo tá longe da Lua, é porque a chuva tá perto da terra. (foco 2)

É... meu avô era um home bem inteligente. Era da roça e conbecia o tempo como ninguém. Ele nunca errô se ia chovê ou fazê tempo bão. (foco 6). [...] Sabe, pensando bem, eu devo sê como o meu avô (foco 6). Sempre que vô sai pra algum lugar, en gosto de assisti à moça do tempo do jornal da TV. A gente tem que se prepará pra tudo, num é? (foco 1 )

Como podemos perceber, tanto nesta entrevista como na próxima, a estrutura do diálogo é diferente do exemplo anterior. Aqui, o pesquisador (P) faz o papel que a criança fazia nos diálogos anteriores (o papel daquele que pergunta e que faz o discurso se desenvolver). Quais focos da aprendizagem informal poderiam ser localizados no diálogo com E1?

A maioria das falas da entrevista está relacionada ao foco 3 (envolvimento com o raciocínio científico). Tais falas aparecem como: fornecimento de explicações, por exemplo, as explicações sobre a poluição (lixo), efeito estufa, formação de nuvens e chuva; elaboração de hipóteses, como na fala: Eu acho que isso tudo tem a vê com a sujera que a gente mesmo faiř, avaliação de evidências, por exemplo, a fala Bão, num sei se é assim mesmo, foi minha filha que aprendeu na iscola outro dia e veio falano isso em casa. $\mathrm{Na}$ entrevista, a pesquisadora também procurou descobrir como a entrevistada buscava as informações científicas que julgava necessárias, uma prática que estaria associada ao foco 5 (envolvimento com a prática e a comunicação científica). No caso de E1, suas fontes de informações foram o rádio, a televisão, pessoas que encontrava no dia a dia e familiares como a filha e o avô. Com relação ao foco 1 (desenvolvimento do interesse pelo conhecimento científico), podemos perceber que, no caso de E1, o seu interesse pelo conteúdo científico está relacionado a problemas práticos de sua vida, como expresso por essas frases: Eu sempre gosto de olha pro céu pra vê se a chuva vem vindo; A gente tem que se prepará pra tudo, num é?. No entanto, pela frase Sabe, pensando bem, eu devo sê como o meu avô, podemos inferir a construção de uma identidade científica (foco 6) por meio da identificação da entrevistada com a maneira como seu avô raciocinava sobre o mundo. Finalmente, evidências de aprendizado do conteúdo científico (foco 2 ) também podem ser encontradas em algumas falas de E1. Uma delas é sua tentativa de pronunciar corretamente a palavra efeito estufa (pronunciando, inicialmente, efeito insufa e, posteriormente, efeito instufa) e quando relata o seu aprendizado sobre a previsão de chuvas pela observação do círculo em roda da Lua.

Entrevista 2 (E2, 59 anos, aposentado. Escolaridade: 3a. série do primário, hoje Fundamental I. Entrevistado no calçadão, centro de Londrina, PR).

P: Ultimamente se tem ouvido falar bastante de problemas ocorridos devido ao excesso de chuvas. O senhor tem se informado sobre esse assunto? 
Arruda, S. M. et al.

E2: Vixe! Se tenho! (foco 1). Cề sabe que no tempo que eu era jovem não acontecia da chuvarada causá tanto probrema que nem hoje. (foco 3). Bão, também naquele tempo a gente nem tinha televisão. Só escutava os programa de rádio e eles nem falava muito disso. (foco 5). [...] Pode ser que o nosso praneta teja mudando e a gente só vê essas mudança quando acontece como agora, muito calor e chuvarada. (foco 3)

P: Mas, para o senhor, qual é a causa disso tudo, ou melhor, o que está provocando esse aumento na temperatura e excesso de chuvas?

E2: Sabe, eu sô pedrero e quando o tempo não tá muito bão, tá com muita chuva, sabe? $O$ ar fica meio úmido e a massa que a gente prepara pra construção fica difícil de dá o ponto e de secá no reboco da parede. Mesmo que onde você passô a massa teja num lugar que não chove. Intão, eu acho... eu acho que a chuva dexa o ar muito úmido e que o reboco precisa de tempo bão pra secá. Bão, esse ar úmido fais formá mais nuve no céu e chove de novo. (foco 3 )

P: O senhor disse que o ar úmido é o responsável pela formação das nuvens. Mas, de onde vem a umidade do ar?

E2: A umidade do ar vem da água que evapora dos lugar que tem água... das água dos rio, da lagoa e até de uma poça de água; tudo que tem água evapora.

(foco 3) O vapor da água fica vagano no ar e forma as nuve que depois que elas tão bem cheia a água cai e assim é que chove. (foco 3)

P: Onde o senhor aprendeu tudo isso?

E2: Eu aprendi essas coisa porque precisava comprendê o tempo já que eu preciso que ele teja bão pra trabaiá; quando chove bastante atrapaia o andamento da obra. (foco 1) [...] Na televisão; sempre tem um pedaço do noticiário que fala do tempo. (foco 5) Nem sempre ele acerta, mas muitas veis dá certinho. (foco 3) Quando num dá pra assisti as notícia da TV, eu procuro sabê do tempo no jornal que o meu vizinho recebe todo dia. Eu impresto dele só pra me informá. (foco1) [...] Também tem o mestre das obra onde eu trabalho e o engenhero que ajuda a gente a percebê essas coisa. (foco 5) Mais, vô te dizê que, mesmo sem tê istudado muito na escola, se a gente vê e prestá atenção nos acontecimento das coisa, a gente aprende como as coisa acontece. (foco 4)

P: O senhor gosta de observar a natureza?

E2: Eu sempre gostei. Desde pequeno olho pro céu, pra repará o tempo (foco 1) e vô te falá que se a gente fais isso com atenção a gente aprende muito. (foco 4) E não é só pro céu que eu costumo olhá. Você sabia que quando tá pra chuvê as furmiga fais correção? (foco 3) [...] As formiga sai tudo das toca delas pra escapá da chuva. Se elas ficam dentro dos buraco morrem porque a chuva inunda tudo. (foco 3) É, mais nem sempre dá pra levá a sério essa andança delas. Elas também pode está só se mudano de toca. (foco 3)

Como na entrevista anterior, a maior parte das falas de E2 recaem sobre o foco 3, sobretudo na modalidade fornecimento de explicações (a umidade do ar vem da água que evapora dos lugar que tem água...). Mas encontramos também a elaboração de hipóteses (Pode ser que o nosso praneta teja mudando...), avaliação de evidências (Nem sempre ele acerta, mas muitas veis dá certinho), 
e, mesmo, realização de perguntas (Você sabia que quando tá pra chuvê as furmiga fais correção?). Com relação ao interesse pelo conhecimento científico (foco 1), E2 revela interesses de ordem prática, diretamente relacionados ao seu trabalho (Eu aprendi essas coisa porque precisava comprendê o tempo já que en preciso que ele teja bão pra trabaiâ).

Esta é também a motivação para a busca do conhecimento (foco 5 - envolvimento com a prática científica), cujas fontes de informação são: a televisão, o jornal (do vizinho), pessoas do trabalho (engenheiro). Entretanto, E2 - realizando uma análise sobre o processo de aquisição de conhecimento (foco 4) - coloca a observação direta da natureza como a fonte maior de aprendizagem (se a gente vê e prestá atenção nos acontecimento das coisa, a gente aprende como as coisa acontece).

\section{Comentários}

As entrevistas mostram o surgimento de vários focos (strands) durante o diálogo. $\mathrm{Na}$ entrevista com E1, foram localizados os focos 1, 2, 3, 5 e 6, enquanto, na entrevista com E2, os focos 1, 3, 4 e 5. Embora haja alguma dificuldade em identificar a qual foco pertence certa frase, podemos afirmar, com certa segurança, que a maioria delas (em ambas as entrevistas) recaiu sobre o foco 3 (uso do raciocínio científico). É possível perceber, igualmente, nas afirmações feitas pelos dois entrevistados, a presença de certo saber sobre o mundo natural, que não poderia ser denominado propriamente de científico, mas que revela que algum conhecimento foi, de fato, construído, evidenciando, portanto, a aprendizagem do tipo especificada no foco 2 .

\section{Conclusões gerais}

Como descrito na introdução, o objetivo deste artigo era o de apresentar evidências de que, no Brasil, assim como em outros países, as pessoas aprendem ciência por livre escolha em situações informais. Fornecemos alguns exemplos de crianças e adultos que, de fato, estão aprendendo ciência no dia a dia, com pessoas próximas do seu círculo de amizade ou, mesmo, com pessoas que encontram na rua, no ônibus etc.

É uma aprendizagem que ocorre de forma contínua, inesperada e que parece estar incorporada à vida cotidiana. Faz parte do viver cotidiano. De modo geral, os entrevistados não demonstraram grande domínio da linguagem científica, mas muitos termos são por eles conhecidos (embora pronunciados de forma errada).

Como a literatura revela, e como confirmado por nossos dados, há diferenças na forma como adultos e crianças se envolvem com o aprendizado informal. As crianças tendem a ter uma curiosidade mais difusa e geral sobre as coisas, abordando assuntos variados de área de conhecimento diferentes, que vão sendo enfileirados, uns após os outros, como um pensamento em rede. As fontes principais de informação das crianças (sobretudo as menores) são os pais e familiares.

Já o interesse dos adultos é mais focado nas necessidades do dia a dia. A curiosidade dos adultos é estimulada por informações que ouvem no rádio e televisão e em conversas com outros adultos. A necessidade de aprender também decorre do trabalho e de outros problemas da vida. 
Arruda, S. M. et al.

Certamente, não se pode dizer, a partir dos dados aqui apresentados, que o aprendizado demonstrado pelos entrevistados ou pelas crianças, nos diálogos de aprendizagem, seja profundo como o que se espera na educação formal ${ }^{10}$. No entanto, ao pensarmos na aprendizagem científica a partir dos focos, podemos compreendê-la não apenas como uma simples apropriação de um conteúdo, mas, também, como um processo em que aspectos importantes para a aprendizagem estão sendo implementados, tais como: o desenvolvimento do interesse pela ciência e da motivação para o aprendizado científico; a prática de um raciocínio sobre os processos naturais, semelhante ao científico; a apropriação de alguns termos da linguagem científica; a utilização de critérios para atribuição de validade ou plausibilidade para afirmações sobre o mundo natural; o desenvolvimento de uma identidade com pessoas que detêm algum saber sobre o mundo ou que detêm algum conhecimento científico etc.

Em síntese, os focos (strands) além de serem um instrumento importante para detectar o aprendizado informal, revelam uma dimensão do aprendizado científico que vai além do que, usualmente, entendemos por isso, enquanto profissionais imersos em sistemas de ensino formais.

${ }^{10}$ Isso não quer dizer que não se pode aprender informalmente ou elaborar conhecimento em quantidade, qualidade e profundidade equivalentes ou, mesmo, superiores à aprendizagem que se obtém em situações de ensino formal. Basta citar, como exemplo, as atividades da Rede de Astronomia Observacional (REA), que se autodefine como uma "Rede informal de observação astronômica amadora, com seus membros espalhados por todo o território nacional, realizando continuamente as observações programadas e registrando seus resultados de forma sistemática" (REDE DE ASTRONOMIA OBSERVACIONAL, 2008). A importância da astronomia amadora também foi abordada em matéria recente na Folha de São Paulo (BARBARA, 2012). 
O aprendizado científico no cotidiano

\section{Referências}

ALVES, D. R. S.; PASSOS, M. M.; ARRUDA, S. M. A educação não formal em periódicos da área de ensino de ciências no Brasil (1979-2008). Revista Brasileira de Ensino de Ciência e Tecnologia, Ponta Grossa, v. 3, n. 1, p. 16-40, 2010.

ANTUNES, F. C. A. A relação com o saber e o estágio supervisionado em Matemática. 2007. 165 f. Dissertação (Mestrado em Ensino de Ciências e Educação Matemática) - Centro de Ciências Exatas, Universidade Estadual de Londrina, Londrina, 2007.

ARRUDA, S. M. Entre a inércia e a busca: reflexões sobre a formação em serviço de professores de física do ensino médio. 2001. 238 f. Tese (Doutorado em Didática) Faculdade de Educação, Universidade de São Paulo, São Paulo, 2001. Disponível em: $<$ http://www.teses.usp.br/teses/disponiveis/48/48133/tde-05032002-132057>. Acesso em: 25 out. 2010.

ARRUDA, S. M.; NARDI, R. Planejamento de curso através da técnica de resolução de problemas: um exemplo. Enseñanza de las Ciencias, Barcelona, v. 10, n. 2, p. 237-240, 1992.

AUSUBEL, D. P.; NOVAK, J. D.; HANESIAN, H. Educational psychology: a cognitive view. New York: Holt, Rinehart and Winston, 1978.

BACCON, A. L. P. O professor como um lugar: um modelo para análise da regência de classe. 2005. 166 f. Dissertação (Mestrado em Ensino de Ciências e Educação Matemática) - Centro de Ciências Exatas, Universidade Estadual de Londrina, Londrina, 2005.

BARBARA, V. Céus!: a quantas anda a astronomia amadora. Folha de São Paulo, São Paulo, 07 out. 2012. Ilustríssima, p. 4-5.

BIANCONI, M. L.; CARUSO, F. Educação não formal. Ciência \& Cultura, São Paulo, v. 57, n. 4, p. 20, 2005.

CHARLOT, B. Formação de professores: a pesquisa e a política educacional. In: PIMENTA, S. G.; GHEDIN, E. (Org.). Professor reflexivo no Brasil: gênese e crítica de um conceito. São Paulo: Cortez, 2005. p. 89-108.

COLLEY, H.; HODKINSON, P.; MALCOLM, J. Non-formal learning: mapping the conceptual terrain, a consultation report. Leeds: University of Leeds, 2002. Disponível em: $<$ http://www.infed.org/archives/e-texts/colley_informal_learning.htm>. Acesso em: 25 out. 2010.

DIERKING, L. D. Lessons without limit: how free-choice learning is transforming science and technology education. História, Ciências, Saúde-Manguinhos, Rio de Janeiro, v. 12, p. 145-160, 2005. (Supplement).

EUROPEAN COMMISSION. Directorate-General for Education and Culture. Making a European area of lifelong learning a reality. Brussels, 2001. Disponível em: <http:// www.bologna-berlin2003.de/pdf/MitteilungEng.pdf>. Acesso em: 25 out. 2010. 
Arruda, S. M. et al.

FENICHEL, M.; SCHWEINGRUBER, H. A. Surrounded by science: learning science in informal environments - based on the National Research Council report Learning science in informal enviroments: people, places, and pursuits. Washington: National Academies Press, 2010.

NATIONAL RESEARCH COUNCIL. How people learn: brain, mind, experience, and school. Washington: National Academies Press, 1999.

Taking science to school: learning and teaching science in grades $\mathrm{K}-8$. Washington: National Academies Press, 2007.

Learning science in informal environments: people, places, and pursuits. Washington: National Academies Press, 2009.

REDE DE ASTRONOMIA OBSERVACIONAL. Sobre nós. [S.l: s.n.], 2008. Disponível em: <http://www.rea-brasil.org/docs/sobre_nos.php>. Acesso em: 09 out. 2010.

SOUSA, A. P. Desânimo: pesquisa revela que razão para baixa frequência de paulistas a teatros e cinemas é falta de interesse. Folha de São Paulo, São Paulo, 20 out. 2010a. Ilustrada, p. E1.

SOUZA, A. P. Esporte é o que mais bem representa cultura brasileira. Folha de São Paulo, São Paulo, 20 out. 2010b. Ilustrada, p. E7.

VIEIRA, V.; BIANCONI, M. L.; DIAS, M. Espaços não formais de ensino e o currículo de ciências. Ciência \& Cultura, São Paulo, v. 57, n. 4, p. 21-23, 2005.

Artigo recebido em 18/08/12. Aceito em 03/11/12. 